ISSN 1808-3765

\title{
UTILIZAÇÃO DE IMAGEM DE SATÉLITE LANDSAT NO MAPEAMENTO DA OCUPAÇÃO DA TERRA E SEUS CONFLITOS DE USO EM APPS NA BACIA HIDROGRÁFICA DO RIBEIRÃO PARAÍSO-SÃO MANUEL (SP).
}

\section{RONALDO ALBERTO POLLO ${ }^{1}$; ZACARIAS XAVIER DE BARROS ${ }^{2}$; YARA MANFRIN GARCIA ${ }^{1}$; GABRIEL RONDINA PUPO DA SILVEIRA ${ }^{1}$; BRUNA SOARES XAVIER DE BARROS ${ }^{3}$ E MARIANA DE CAMPOS}

\footnotetext{
${ }^{1}$ Pós-Graduandos do Programa de Pós Graduação em Agronomia / Energia na Agricultura - Departamento de Engenharia Rural FCA/UNESP, Botucatu/SP, Rua José Barbosa de Barros, no 1780. E-mail: \{rapollo, yaramanfrin, grpdsilveira\}@fca.unesp.br

Prof $^{\text {. }}$ Titular do Departamento de Engenharia Rural, FCA/UNESP - Botucatu/SP. E-mail: zacariasxb@fca.unesp.br

${ }^{3}$ Prof $^{\mathrm{a}}$. Substituta do Departamento de Engenharia Rural, FCA/UNESP - Botucatu/SP. E-mail: brunasxb@hotmail.com
}

\section{RESUMO}

O presente trabalho teve como objetivos principais avaliar por meio de imagem TM (Thematic Mapper) do satélite Landsat-5 de 2010, o uso e ocupação da terra, as Áreas de Preservação Permanentes segundo o Código Florestal e seus conflitos de uso, por meio de Sistemas de Informações Geográficas (SIG) na bacia hidrográfica do ribeirão Paraíso, município de São Manuel - SP. A combinação das tecnologias de Sensoriamento Remoto e dos Sistemas de Informações Geográficas permitiram uma representação da distribuição espacial da paisagem e uma integração de dados no diagnóstico de interesse geográfico. $\mathrm{O}$ mapeamento de 2010 resultou em doze classes de uso, demonstrando a maior ocupação do solo com a cultura da cana-de-açúcar ocupando 48,25\% da área. As Áreas de Preservação Permanente totalizaram 925,74ha como um valor ideal fundamentadas na legislação brasileira, onde os mapas de conflito de uso da terra evidenciaram intensa ação antrópica, onde avançaram 80,13\% sobre as Áreas de Preservação Permanente restando apenas 19,87\% de seus remanescentes florestais revelando o impacto negativo e situação irregular sobre estas áreas.

Palavras-chave: Sensoriamento remoto; Bacia hidrográfica; Uso e ocupação do solo; Sistemas de Informações Geográficas.

POLLO, R. A.; BARROS, Z. X. de; GARCIA, Y. M.; SILVEIRA, G. R. P. da; BARROS, B. S. X. de; CAMPOS, M. de WATERSHED OF RIBEIRÃO PARAÍSO, SÃO MANUEL, SP, BRAZIL 


\section{ABSTRACT}

The objectives of this study were to evaluate land use and occupation of Permanent Preservation Areas (PPA) as well as its use conflicts by TM (Thematic Mapper) image of the 2010 Landsat-5 satellite, according to the Forest Code. For that purpose, Geographic Information Systems in the Ribeirão Paraíso watershed, São Manuel, SP were used. The combination of Remote Sensing and Geographic Information System technologies allowed representation of spatial distribution of the landscape and data integration in the diagnosis of geographic interest. The 2010 mapping showed 12 use categories, and the sugar cane crop had the largest land occupation, $48.25 \%$ of the area. The areas of permanent preservation amounted to 925.74 ha, which is an ideal value based on the Brazilian legislation. Mapping of land use conflicts showed intensive anthropic actions going $80.13 \%$ forward on PPAs, with only $19.87 \%$ remaining forests, which highlights their negative impact and illegal situations in these areas.

Keywords: Remote sensing; watershed; land use and occupation; geographic information systems.

\section{INTRODUÇÃO}

$\mathrm{Na}$ busca pelo desenvolvimento econômico, as ações antrópicas em seus mais variados modelos de produção, alteraram o meio ambiente configurando diversas formas de riscos ambientais, onde uma recuperação dos recursos naturais se torna urgente, exigindo conhecimentos que permitam avaliar os impactos e as situações de riscos, visando o planejamento e intervenções para o estabelecimento de ações de recuperação ambiental.

Segundo Nardini (2009), o levantamento do uso do solo, em uma determinada região, torna-se um aspecto de interesse fundamental para a compreensão dos padrões de organização do espaço já que o conhecimento das alterações ambientais, provocadas pela ação antrópica, possibilita uma visão dos problemas existentes e produz subsídios para gestão dos recursos naturais. É condição primordial para se programar uma política de uso racional do solo e de respeito à suscetibilidade e capacidade de suporte do meio ambiente aos impactos antrópicos, possibilitando o desenvolvimento sócio-econômico sustentável.

A intervenção antrópica de maneira desordenada e sem observância de critérios mínimos de práticas conservacionistas de uso e manejo do solo, tem acarretado sérios danos ambientais, atingindo o solo, a flora, a fauna, os mananciais e o homem, provocando uma piora em sua qualidade de vida (PEREIRA et al., 2002).

Para Garcia (2012), a legislação ambiental brasileira é considerada uma das legislações mais avançadas do mundo, estando de acordo com a importância da preservação do meio ambiente, porém, esta nem sempre é aplicada e fiscalizada de maneira adequada, sabendo que em muitas situações a degradação ambiental pode afetar de forma direta a qualidade de vida da sociedade.

A alteração da cobertura da terra ocorre com grande rapidez em extensas áreas do território brasileiro, assim como em outras regiões do mundo (CORGNE; ROBIN, 2000). Panizza e Fournier (2006) afirmam que a expansão agrícola e o crescimento urbano são responsáveis por parte expressiva dessas alterações. O desenvolvimento de novas tecnologias como os Sistemas de Informações Geográficas (SIGs) tem colaborado na quantificação destas alterações, possibilitando ações de recuperação por tomadores de decisão, onde um grande 
volume de informações são cruzadas, facilitando e sugerindo diversas abordagens sobre o planejamento do uso do solo.

O presente trabalho teve como objetivo avaliar o uso e ocupação do solo, as Áreas de Preservação Permanentes (APPs) segundo o Código Florestal e seus conflitos de uso, por meio de Sistemas de Informações Geográficas na bacia hidrográfica do ribeirão Paraíso, município de São Manuel - SP.

\section{MATERIAL E MÉTODOS}

A bacia hidrográfica do ribeirão Paraíso localiza-se no município de São Manuel-SP, entre as coordenadas UTM 752000 a 743650 E e 7478150 a 7495350 N, fuso $22 \mathrm{~K}$ distando aproximadamente $270 \mathrm{Km}$ da capital do estado. Neste trabalho a bacia hidrográfica foi estudada dentro do município de São Manuel até o limite a noroeste com o município de Areiópolis-SP à sua jusante, possuindo uma área de 8.737,47 hectares (ha). Parte da área objeto de estudo, encontra-se inserida na Área de Proteção Ambiental (APA) Perímetro Botucatu-SP (SÃO PAULO, 1983), considerada uma área de recarga do Aquífero Guarani, pertencente ao Sistema Nacional de Unidades de Conservação (BRASIL, 2000).

Para o apoio cartográfico, foram utilizadas cartas planialtimétricas editadas pelo Instituto Brasileiro de Geografia e Estatística (IBGE) em formato impresso e digital em escala 1:50.000 com equidistância das curvas de nível de 20 metros referente a Folha de São Manuel/SF-22-Z-B-V-2, e Pratânia/SF-22-Z-B-V-4 (IBGE, 1973).

Utilizou-se imagem do sensor TM (Thematic Mapper) do satélite Landsat-5 de 19/11/2010 da órbita 220, ponto 76, com resolução espacial de 30 x 30 metros fornecida pelo Instituto Nacional de Pesquisas Espaciais (INPE), que possui sete bandas espectrais das quais, para este trabalho, foram utilizadas apenas três bandas $(3,4$ e 5), pois estas são as que correspondem às respostas espectrais de alvos úteis ao mapeamento de uso da terra.

Também foi utilizado o editor vetorial CartaLinx 1.2, Hagan et al. (1998), que define características espaciais em formato vetorial de arquivos codificados como limite das áreas de diferentes usos da terra e da drenagem. Utilizou-se também o Sistema de Informação Geográfica, SIG - IDRISI Selva edição 17.0, (EASTMAN, 2012) para a rasterização das imagens que foram importadas do CartaLinx.

Com as bandas das imagens georreferenciadas, foi realizado o processo de composição da imagem RGB (Red, Green, Blue), utilizando-se da função Composite do menu Display do IDRISI. Para a composição do vermelho (R), verde (G) e azul (B) foram utilizadas as bandas 3,4 e 5 , respectivamente.

Após a composição, efetuou-se o recorte da imagem através da opção Reformat/Window extraindo assim apenas a área da bacia.

Após o recorte da área de estudo, no software CartaLinx foi realizada a interpretação visual em tela, onde as áreas com cobertura vegetal foram classificadas sobre as composições coloridas, ampliadas em tela para melhor visualização.

Para a elaboração dos polígonos de uso e cobertura, criou-se uma tabela, através do menu Tables/Add Fields e em cada polígono através do comando polígono locator e feature properties colocava-se o número correspondente a classe de uso como 1-Área Urbana; 2Mata; 3-Reflorestamento; 4-Pínus; 5-Café; 6-Represa; 7-Várzea; 8-Outras Culturas; 9-ETESABESP; 10-Cana-de-açúcar; 11-Pastagem; 12-Aterro Sanitário.

Para auxiliar na interpretação visual das áreas de cobertura vegetal, já que em análise geral percebeu-se que a resolução e consequentemente a qualidade era insuficiente para a 
classificação de variações agrícolas e florestais, utilizou-se uma imagem do satélite SPOT de 26/07/2010 de seu banco de imagens de alta resolução espacial disponibilizado por Google Earth (2010), com resolução espacial de 15 metros, servindo de apoio e permitindo delimitar com maior detalhe as nascentes extraídas das cartas planialtimétricas e os limites das áreas de interesse, o qual possibilitou a identificação de 12 classes de uso e cobertura para o ano de 2010 por meio da imagem de satélite. De posse do arquivo completo vetorizado, o mesmo foi exportado para o IDRISI.

Através do comando Area do menu Database Query, pertencente ao módulo Analysis, foram determinadas as áreas e as porcentagens de cada uso.

Desta forma, definiram-se as Áreas de Preservação Permanente ao longo dos cursos d'água e ao redor das nascentes do ribeirão Paraíso, utilizando-se da operação buffer do SIG IDRISI Selva, que proporcionou a criação de um raio de 50 metros circulando as áreas das nascentes e um buffer de 30 metros de cada lado da margem na drenagem ao longo do leito do ribeirão, resultando no mapa de APPs.

Para estas medidas, levou-se em consideração a largura dos cursos d'água, que são inferiores a 10 metros na área estudada, e estão fundamentadas na legislação brasileira mais especificamente, o Código Florestal através da Lei $\mathrm{n}^{\circ} 12.651$ alterada pela Lei $\mathrm{n}^{\mathrm{o}} 12.727$, que em seu Capítulo II - Art. $4^{\circ}$ institui “Área de Preservação Permanente a área situada em faixa marginal de qualquer curso d’água natural perene e intermitente, excluídos os efêmeros, medida a partir da borda da calha do curso regular, em projeção horizontal, com largura mínima de trinta metros para o curso d'água com menos de 10 metros de largura", e, "áreas no entorno das nascentes e dos olhos d’água perenes, qualquer que seja sua situação topográfica, no raio mínimo de 50 (cinquenta) metros" (BRASIL, 2012). A palavra buffer conforme Teixeira e Christofoletti (1997), em ambiente SIG, significa uma forma de análise de proximidade onde zonas de uma determinada dimensão são delimitadas em volta de uma feição ou de um elemento geográfico, levando-se em conta um determinado atributo.

Para quantificar as áreas de conflitos de uso do solo em Áreas de Preservação Permanentes, utilizou-se a álgebra de mapas (operação da multiplicação) realizando a sobreposição do mapa de uso e ocupação do solo com o mapa das APPs. Os procedimentos foram executados no SIG - IDRISI Selva utilizando-se a ferramenta overlay menu Mathematical Operators. Após a sobreposição dos mapas, as áreas de ocorrência dos conflitos foram identificadas e devidamente mensuradas, executando as funções de cálculo de área, através da ferramenta Area do menu Database Query, pertencente ao módulo Analysis do SIG-IDRISI Selva. Foram consideradas sob uso conflitante todas as áreas cultivadas presentes nas APPs das nascentes e cursos d'água.

\section{RESULTADOS E DISCUSSÃO}

\subsection{Uso e ocupação do solo}

O mapeamento das áreas de uso e ocupação do solo na bacia hidrográfica do ribeirão Paraíso-SP, totalizaram 12 classes de uso conforme a Figura 1. 
Figura 1. Mapa do uso e ocupação do solo na bacia hidrográfica do ribeirão Paraíso- São Manuel (SP).

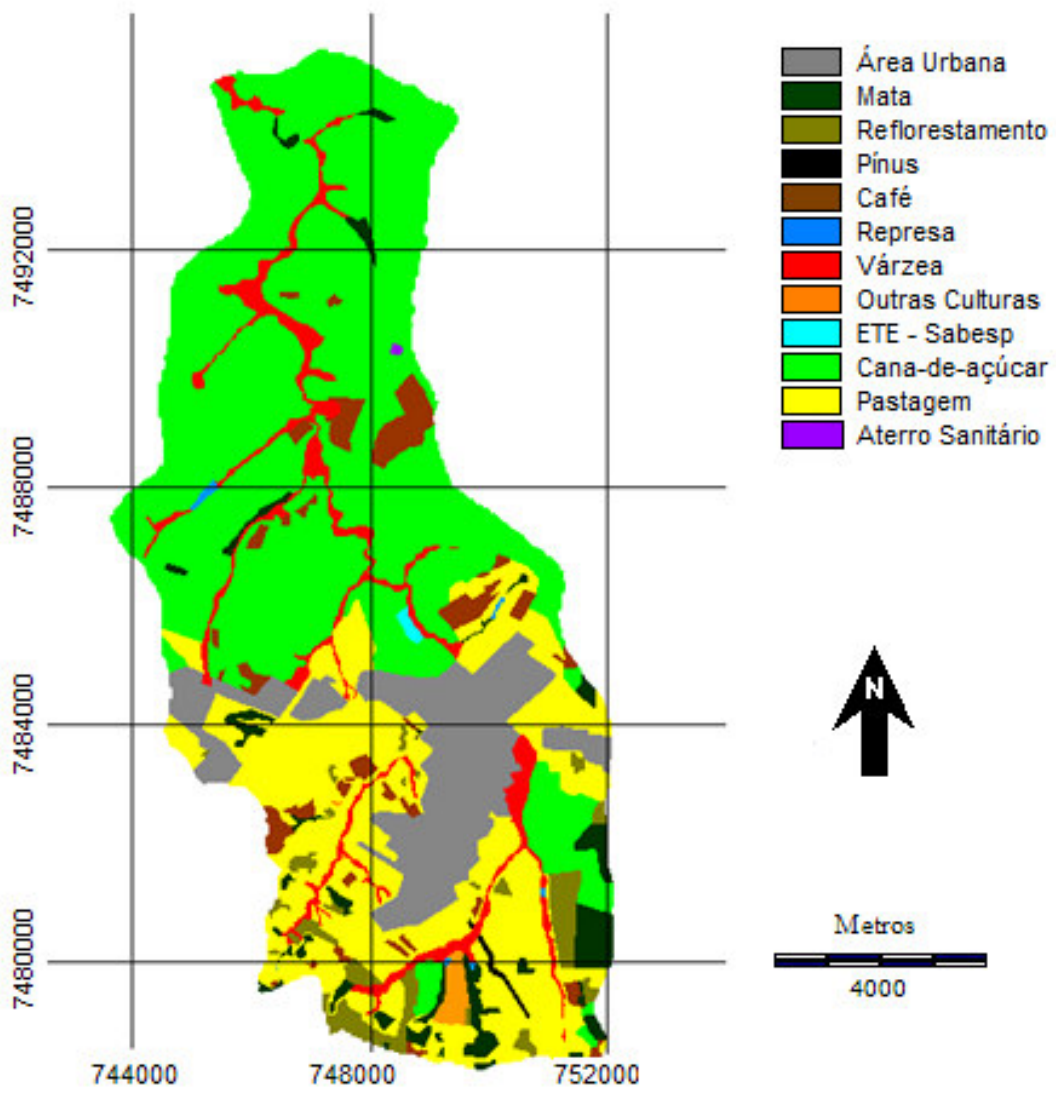

Analisando a Figura 1 e os valores das áreas obtidos em hectares na Tabela 1, constata-se a predominância da cana-de-açúcar, indicando com isto a importância desta cultura na bacia estudada.

Tabela 1. Distribuição das áreas e porcentagens de uso e ocupação do solo em 2010.

\begin{tabular}{lcc}
\hline \multicolumn{1}{c}{ Usos } & \multicolumn{2}{c}{ Área } \\
\cline { 2 - 3 } & $\mathbf{( h a )}$ & $\mathbf{( \% )}$ \\
\hline Área Urbana & 997,52 & 11,42 \\
Mata & 316,00 & 3,62 \\
Reflorestamento & 241,56 & 2,76 \\
Pínus & 16,02 & 0,18 \\
Café & 333,70 & 3,82 \\
Represa & 13,82 & 0,16 \\
Várzea & 497,74 & 5,70 \\
Outras Culturas & 47,08 & 0,54 \\
ETE - SABESP & 12,11 & 0,14 \\
Cana-de-Açúcar & $4.216,24$ & 48,25 \\
Pastagem & $2.042,33$ & 23,37 \\
Aterro Sanitário & 3,35 & 0,04 \\
\hline Total & $8.737,47$ & 100,00 \\
\hline
\end{tabular}


Ainda, segundo a Tabela 1 pode-se constatar que cultura da cana-de-açúcar aparece com 4.216,24ha $(48,25 \%)$ da área, seguida pela pastagem com 2.042,33ha $(23,37 \%)$; área urbana com 997,52ha (11,42\%); várzea com 497,74ha $(5,70 \%)$; café com 333,70ha $(3,82 \%)$; mata com 316,00 ha $(3,62 \%)$; reflorestamento com 241,56ha $(2,76 \%)$; outras culturas com 47,08ha $(0,54 \%)$; pínus com 16,02ha $(0,18 \%)$; represa com 13,82 ha $(0,16 \%)$; ETE (Estação de Tratamento de Esgotos)-SABESP 12,11ha (0,14\%) e aterro sanitário com 3,35ha (0,04\%), mostrando que a cultura canavieira teve sua maior extensão de ocupação na parte centro/norte da área de estudo, áreas estas constituídas por grandes fazendas, que favorecidas pela logística rural, foram aos poucos sendo incorporadas e arrendadas por uma unidade produtora de açúcar e álcool instalada no município.

Representando uma área de 4.216,24ha que corresponde a 48,25\% do total da bacia, Tabela 1, a expansão da cultura da cana-de-açúcar foi motivada, principalmente pela criação do Programa Nacional do Álcool (Proálcool), BRASIL (1975), com o objetivo de estimular a produção do álcool, visando a substituição em larga escala dos derivados de petróleo, onde, associada a modernização dos métodos de cultivo agrícola incrementou o desenvolvimento desta cultura na região, gerando com isto a substituição de culturas antes tradicionais pela cultura canavieira.

\section{Áreas de Preservação Permanentes (APPs) e seus conflitos de uso do solo ao redor das nascentes e cursos d'água}

A Figura 2 mostra a condição ideal de como deveriam estar as Áreas de Preservação Permanentes $(925,74 \mathrm{ha})$ e parte da APA-perímetro Botucatu-SP na bacia estudada.

Figura 2. Áreas de Preservação Permanente ao longo dos cursos d'água e nas nascentes na bacia do ribeirão Paraíso (SP) e parte da APA - perímetro Botucatu (SP).

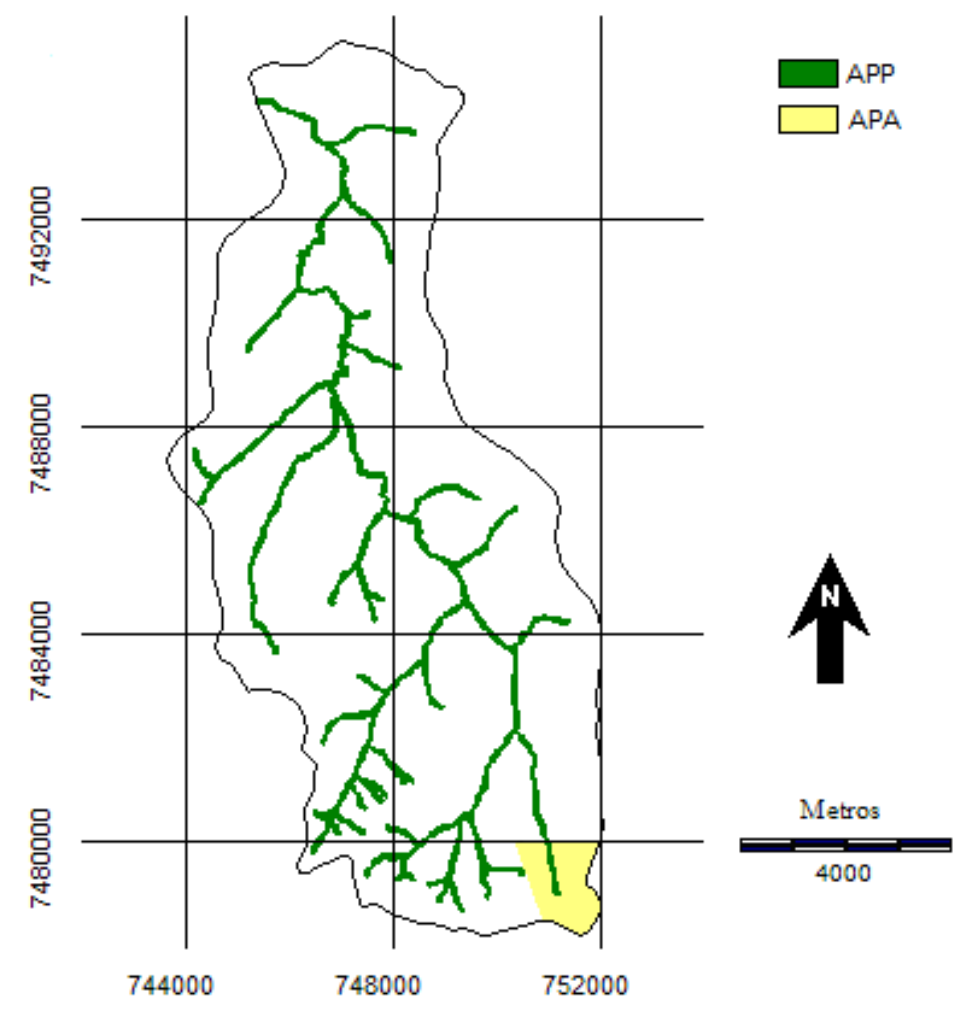


Analisando a Figura 3 a seguir, constata-se nitidamente os conflitos de uso do solo em APPs, em função das alterações provocadas pela ação antrópica, onde um total de dez classes de conflitos de uso foi encontrado para o ano de 2010.

Figura 3. Mapa de conflito de uso do solo em APPs no ano de 2010.

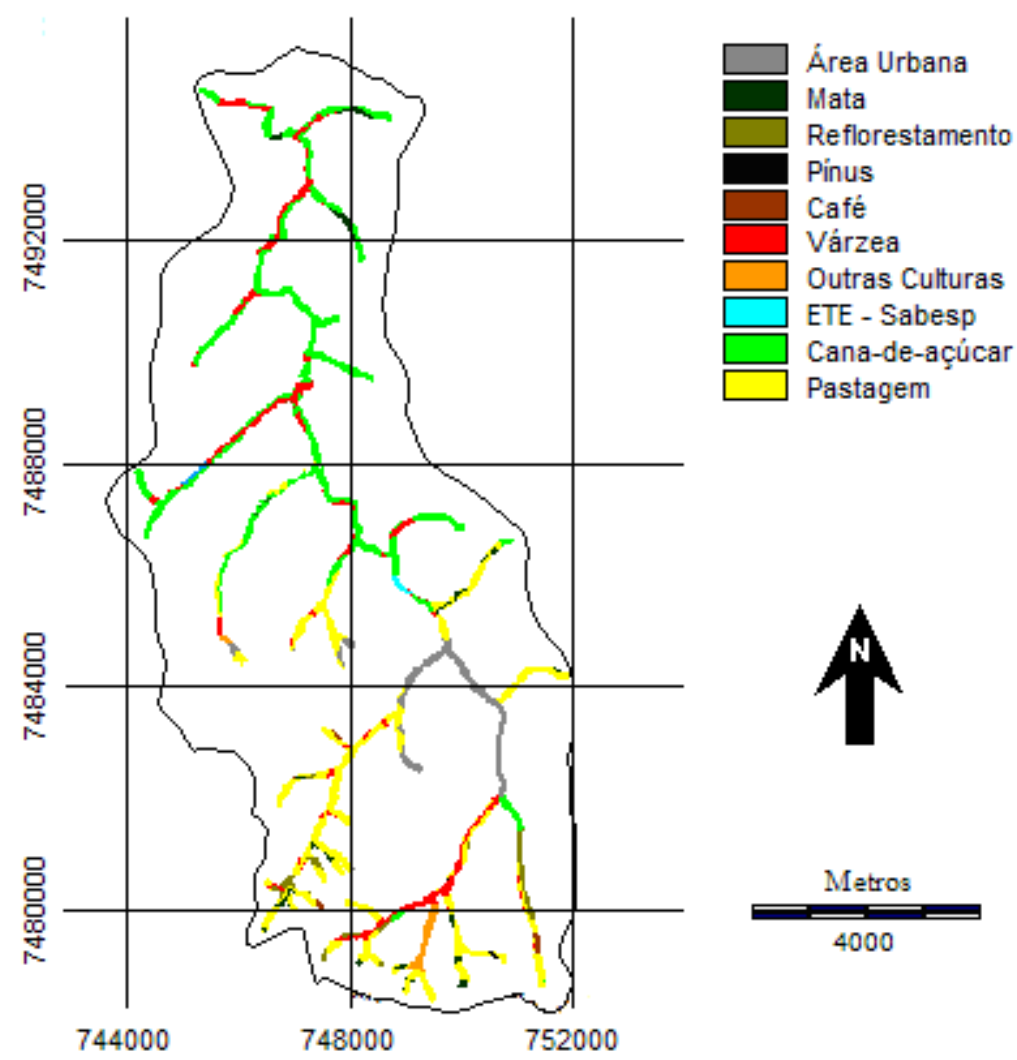

A Tabela 2 apresenta em 2010 um total de conflito de uso de 741,73ha perfazendo um total de $80,13 \%$ das áreas destinadas as APPs, restando apenas 19,87\% com áreas preservadas, mostrando uma situação irregular, onde a grande pressão exercida pelas atividades agrícolas geraram conflitos de uso do solo na bacia estudada revelando o impacto negativo e mudanças aceleradas sobre estas áreas.

Constatou-se que a cana-de-açúcar avançou 336,75ha (36,38\%) sobre as APPs, seguida pela pastagem com 284,99ha (30,79\%), área urbana com 53,55ha $(5,78 \%)$, reflorestamento com 30,54 ha $(3,30 \%)$, outras culturas com 18,41ha $(1,99 \%)$, café com 13,51 ha $(1,46 \%)$, ETE-SABESP com 2,69 ha $(0,29 \%)$ e com o menor conflito de uso a cultura com pínus com 1,29 ha $(0,14 \%)$. 
Tabela 2. Conflitos de uso do solo em APPs em 2010.

\begin{tabular}{lcccc}
\hline $\begin{array}{c}\text { Classes de Uso } \\
\text { do solo }\end{array}$ & \multicolumn{2}{c}{$\begin{array}{c}\text { Uso e Ocupação } \\
\text { em }\end{array}$} & APPs & \multicolumn{2}{c}{$\begin{array}{c}\text { Conflitos nas } \\
\text { APPs }\end{array}$} \\
\hline Área Urbana & 53,55 & \% & ha & \% \\
Mata & 40,22 & 4,34 & 53,55 & 5,78 \\
Reflorestamento & 30,54 & 3,30 & 30,54 & - \\
Pínus & 1,29 & 0,14 & 1,29 & 0,14 \\
Café & 13,51 & 1,46 & 13,51 & 1,46 \\
Represa & 3,83 & 0,41 & - & - \\
Várzea & 139,96 & 15,12 & - & - \\
Outras Culturas & 18,41 & 1,99 & 18,41 & 1,99 \\
Cana-de-açúcar & 336,75 & 36,38 & 336,75 & 36,38 \\
Pastagem & 284,99 & 30,79 & 284,99 & 30,79 \\
ETE-SABESP & 2,69 & 0,29 & 2,69 & 0,29 \\
\hline Total & 925,74 & 100 & 741,73 & 80,13 \\
\hline
\end{tabular}

Oliveira e Perez Filho (1993) chamam a atenção para a implantação de culturas agrícolas em áreas próximas às nascentes de rios, que se cultivadas com uso de fertilizantes, adubos e agrotóxicos, podem contaminar cursos d'água incluindo reservatórios de abastecimento para populações humanas. Na Figura 3, a cultura da cana-de-açúcar apresenta conflito de uso em nascentes e ao longo dos cursos d'água.

A área de pastagem que aparece em segundo lugar em áreas conflitivas (Tabela 2) geograficamente, se apresenta em posição preocupante (Figura 3), pois está próxima de uma importante nascente do córrego da Igualdade que serve de abastecimento de água à população, comércio e indústrias do município de São Manuel-SP. No local existem centros de manejo de bovinos onde o gado tem acesso facilitado à nascente, sendo que as APPs deveriam estar preservadas com o objetivo de proteger o ambiente natural, com 50 metros de raio para a nascente e 30 metros de cada lado da margem do rio por apresentar largura inferior a 10 metros. Esta área ocupada por pastagem está inserida totalmente na Área de Proteção Ambiental (APA) Perímetro-Botucatu-SP (SÃO PAULO, 1983), considerada uma área de recarga do Aquífero Guarani (Figura 2), pertencendo ao Sistema Nacional de Unidades de Conservação (BRASIL, 2000), onde esta área deveria ter maior atenção e fiscalização mais efetiva.

Também foi mapeado o conflito de uso do solo em áreas urbanas, onde as faixas de preservação ambiental cedem lugar para as construções.

As espécies vegetais exóticas invasoras também apresentam conflitos de uso do solo em vários locais ao longo dos cursos d'água, ocupando as Áreas de Preservação Permanentes que deveriam possuir 30 metros de cada borda com vegetação natural.

A Estação de Tratamento de Esgotos-SABESP do município de São Manuel-SP, com uma área de 12,11ha, Tabela 1, está em conflito de uso com 2,69ha, Tabela 2, demonstrando impactos de sua implantação local sobre as APPs. 


\section{CONCLUSÕES}

O mapeamento do uso e ocupação do solo de 2010 na bacia hidrográfica do ribeirão Paraíso- São Manuel/SP mostrou que a cultura canavieira e as pastagens foram as ocupações que apresentaram os maiores valores encontrados: $48,25 \%$ e $23,37 \%$ respectivamente.

O mapa de conflito de uso do solo de 2010 apresentou resultados que evidenciam a grande pressão exercida pelas atividades agrícolas na modificação da paisagem natural, gerando conflitos de uso do solo na bacia estudada, onde avançaram $80,13 \%$ sobre as Áreas de Preservação Permanentes, restando apenas $19,87 \%$ de seus remanescentes florestais, revelando o impacto negativo e mudanças aceleradas sobre estas áreas.

\section{REFERÊNCIAS BIBLIOGRÁFICAS}

BRASIL. Lei $\mathrm{n}^{\circ} 76.593$ de 14 de novembro de 1975. Institui o Programa Nacional do Álcool e dá outras Providências. Diário Oficial da União, Brasília, DF,14 de nov. 1975. P.15257. Disponível em:< http://www2.camara.leg.br/legin/fed/decret/1970-1979/decreto-76593-14novembro-1975-425253-publicacaooriginal-1-pe.html>. Acesso em: 15 abr. 2013. Seção 1.

Lei $\mathrm{n}^{\circ} 9.985$ de 18 de julho de 2000. Regulamenta o art. 225, § 1o, incisos I, II, III e VII da Constituição Federal, institui o Sistema Nacional de Unidades de Conservação da Natureza e dá outras providências. Constituição Federal. Brasília, DF, 18 jul. 2000. Disponível em: <http://www.planalto.gov.br/ccivil_03/leis/19985.htm>. Acesso em: 14 mar. 2013.

Lei $\mathrm{n}^{\circ} 12.727$ de 17 de outubro de 2012. Altera a Lei $\mathrm{n}^{-} 12.651$, de 25 de maio de 2012, que dispõe sobre a proteção da vegetação nativa; altera as Leis nos 6.938 , de 31 de agosto de 1981, 9.393, de 19 de dezembro de 1996, e 11.428, de 22 de dezembro de 2006; e revoga as Leis $\mathrm{n}^{\text {os }} 4.771$, de 15 de setembro de 1965, e 7.754, de 14 de abril de 1989, a Medida Provisória n⿳0 2.166-67, de 24 de agosto de 2001, o item 22 do inciso II do art. 167 da Lei $\mathrm{n}^{\mathrm{o}} 6.015$, de 31 de dezembro de 1973 , e o $\S 2^{\circ}$ do art. $4^{\circ}$ da Lei $\mathrm{n}^{\mathrm{o}} 12.651$, de 25 de maio de 2012. Presidência da República. Casa Civil. Brasília, DF, 17 de out. 2012. Disponível em: <http://www.planalto.gov.br/ccivil_03/_Ato2011-2014/2012/Lei/L12727.htm>. Acesso em: 25 de abr. 2013.

CORGNE, S.; ROBIN, M. Evolution de l'occupation du sol à la périphérie du Parc National de Taï (Côte d'Ivoire). Photo-interprétattion, nº 1/2, p. 40-46, 2000.

EASTMAN, J. R. IDRISI Selva - GIS and Image Processing Software - version 17.0. Worcester-MA/USA: Clark Labs, 2012.

GARCIA, Y. M. O Código Florestal Brasileiro e suas mudanças no Congresso Nacional. Revista GeoAtos. Departamento de Geografia da FCT/UNESP, Presidente Prudente, n. 12, v.1, jan.-jun. de 2012, p.54-74.

GOOGLE EARTH. Google Inc, 2010. Disponível em: <earth.google.com/>. Acesso em: 03 fev. 2013. 
HAGAN, J. E.; EASTMAN, J. R.; AUBLE, J. CartaLinx: the spatial data builder users guide. Clark University. Massachusets, 1998.

INSTITUTO BRASILEIRO DE GEOGRAFIA E ESTATÍSTICA. Carta topográfica: folhas São Manuel - SF-22-Z-B-V-2 e Pratânia - SF-22-Z-B-V-4. Rio de Janeiro: Serviço gráfico do IBGE, 1973. Escala 1:50.000.

INPE. INSTITUTO NACIONAL DE PESQUISAS ESPACIAIS - Divisão de Geração de Imagens (DGI-INPE). Catálogo de Imagens. São José dos Campos，2010. Disponível em:<http://www.dgi.inpe.br/>. Acesso em: 03 mar. 2013.

NARDINI, R. C. Determinação do conflito de uso e ocupação do solo em áreas de preservação permanente da microbacia do ribeirão Água-Fria, Bofete (SP), visando a conservação dos recursos hídricos. 2009. 61f. Dissertação (Mestrado em Agronomia/Irrigação e Drenagem)-Faculdade de Ciências Agronômicas, Universidade Estadual Paulista. Botucatu-SP. UNESP. 2009.

OLIVEIRA, P.S.G.; PEREZ FILHO, A. Aplicação da fotografia aérea na recomposição da mata ciliar em bacias hidrográficas. In: CONGRESSO BRASILEIRO DE ENGENHARIA AGRÍCOLA, 22, 1993, ILHÉUS. Resumos... Ilhéus: Comissão Executiva do Plano da Lavoura Cacaueira, 1993. p.441-55.

PANIZZA, A. C.; FOURNIER, J. Forêt atlantique, entre l'occupation et préservation. Grafigéo, Paris, n.30, p.59-67, 2006.

PEREIRA, E. A.; SOUSA; A. P.; CAMPOS, S. Mapeamento do uso do solo nas sub-bacias dos córregos São José e Água do Ventura, Bauru (SP). Revista Irriga. Botucatu-SP v.7, n.3 p. 191-200, 2002.

SÃO PAULO. Decreto Estadual no 20.960, de 8 de junho de 1983. Área de Proteção Ambiental: São Paulo. Diário Oficial v.96, n.002,1983. Disponível em: <http://www.ambiente.sp.gov.br/apas/20960.htm>. Acesso em: 23 ago. 2012.

TEIXEIRA, A.L.A.; CHRISTOFOLETTI, A. Sistema de Informações Geográficas: dicionário ilustrado. São Paulo: Editora Hucitec, 1997. 